\title{
INADEQUACY OF N-3 POLYUNSATURATED FATTY ACID DIETARY INTAKES IN THE GENERAL FRENCH POPULATION OF ELDERLY (65 TO 79 YEARS OLD): THE INCA 2 SURVEY
}

\author{
B. Buaud ${ }^{1}$, J. Tressou' ${ }^{2}$ P. Guesnet ${ }^{3}$, N. Simon ${ }^{4}$, S. Pasteau ${ }^{5}$
}

\begin{abstract}
Objectives: The aim of this study was to explore polyunsaturated fatty acid (PUFA) intakes in the French elderly population (65 to 79 years old). Design: The study used data on French food consumption issued from 348 elderly of the crosssectional national French INCA 2 dietary survey performed in 2006 and 2007, combined with the nutritional content of food consumed updated in 2013 by the French Information Center on Food Quality. Results: It was observed for the French elderly population an adequate total fat daily intake and a linoleic acid (LA) daily intake close or superior to the recommended dietary intake (RDI) by the French authorities (from 4.1 to $4.4 \%$ of the total energy intake excluding alcohol (EIEA) vs $4 \%$ EIEA). By contrast, the French elderly have, regardless of age and gender, a low mean dietary alpha-linolenic acid (ALA) intake equal half of the RDI (0.5\% EIEA vs 1\% EIEA), and a mean dietary docosahexaenoic acid (DHA) intake close to two-thirds of the RDI (i.e. from 154 to $167 \mathrm{mg} / \mathrm{d}$ vs $250 \mathrm{mg} / \mathrm{d}$ ). These translated into a LA/ALA ratio between 9.5 and 9.9, twice as high as the recommended threshold inferior to 5, and a mean dietary eicosapentaenoic acid (EPA) plus DHA intake (from 267 to $293 \mathrm{mg} / \mathrm{d}$ ) slightly more than half of the RDI $(500 \mathrm{mg} / \mathrm{d})$. Conclusion: This study supports the need to promote higher intakes of n-3 PUFAs, as well as the setting of specific intake recommendations for these fatty acids for the French elderly population.
\end{abstract}

Key words: n-3 polyunsaturated fatty acids, dietary intakes, dietary recommendations, INCA 2 survey, elderly.

\section{Introduction}

Polyunsaturated fatty acids (PUFAs) include n-6 and n-3 fatty acids. Linoleic acid (18:2n-6, LA), and alphalinolenic acid (18:3n-3, ALA), the precursors of $n-6$ and n-3 series respectively, are both essential fatty acids that cannot be synthesized by humans and must be supplied with the diet. Beneficial effects of LA have been reported on blood lipid profile, and its association with a lower risk of coronary heart disease (CHD) events and reduced risk of type 2 diabetes (1). Although clinical benefits have not been observed across all studies, several experimental and prospective observational studies support that ALA consumption reduces the incidence of CHD (2). N-3 long-chain PUFAs eicosapentaenoic (20:5n-3, EPA) and docosahexaenoic acids (22:6n-3, DHA), that are essentially derived from marine sources, and to a lesser extent issued from the conversion of ALA which occurs at a very low rate in humans, have demonstrated physiological benefits on blood pressure, heart rate, triglycerides, and likely inflammation,

1. ITERG - Institut des Corps Gras, Canéjan, France; 2. UMR MIA-Paris, AgroParisTech, INRA, Université Paris-Saclay, Paris, France; 3. PG Consulting, Bures sur Yvette, France; 4. Terres Univia, Paris, France; 5. Phasme Consulting, Paris, France.

Corresponding Author: Benjamin Buaud, ITERG - Institut des Corps Gras, Canéjan, France, E-mail: b.buaud@iterg.com; Phone: (33)557575728; Fax: (33)557575732. endothelial function, and cardiac diastolic function [3]. In France, where life expectancy is among the highest in the world, the older population has specific nutritional requirements in order to avoid malnutrition and also more subtle deficiencies due to the current imbalanced Western diets. To this end, there is a growing interest in the putative protective effects of n-3 PUFAs against cardiovascular disease, cancer and neuro-psychiatric disorders, whose incidence sharply increases with age (4). But although n-3 PUFAs seem essential as enhancers to be consumed for the promotion of healthy aging, no specific dietary recommendations are formulated for elderly in France as in many European countries. Several international and national organizations have indeed proposed recommended dietary intakes (RDIs) for PUFAs for specific population groups (such as pregnant and lactating women, infants, children and adolescents) and for the general adult population, while specifying that the RDI of adults could also be valid for the elderly (5). As reported by a recent review, the intake of PUFAs, notably n-3 PUFAs, is suboptimal in many European countries (5), like it has been showed in France by the data from the cross-sectional national French INCA 2 dietary survey (2006-2007) (6). Evaluated against the French Agency for Food, Environmental and Occupational Health \& Safety (ANSES) recommendations (7), only $2.3,7.8$, and $14.6 \%$ of the French adult population met RDIs for ALA, EPA, and 
DHA respectively. Since very few studies have focused on PUFA intake of French elderly, the objective of our study was to explore PUFA intakes in French elderly ( $\geq 65$ and $\leq 79$ years old, both genders) using the data on French food consumption issued from the French National Survey INCA 2 performed in 2006 and 2007, combined with the nutritional content of food consumed updated in 2013 by the French Information Center on Food Quality (8).

\section{Material and methods}

Following the same methodology as in Tressou et al. (6), INCA 2 data was combined to the ANSES Ciqual 2013 composition database (https://pro.anses.fr/ TableCIQUAL/) to compute intakes of all fatty acids for the 348 adults aged from 65 to 79 years old. The group was further divided into 3 subgroups 65-69, 70-74, and 75-79 years old with sizes 150,114, 84, respectively, and a mean female ratio of $56.6 \%$ (60\% for $65-69 \mathrm{y}, 55.3 \%$ for $70-74 \mathrm{y}$, and $52.4 \%$ for $75-79 \mathrm{y}$ ). This is sufficient to compute statistics by age group and by gender. As in Tressou et al. (6) and as recommended by ANSES, results are balanced using the weights provided in the INCA 2 database to get results that are representative of the French population. Calculations are performed with survey package of the $\mathrm{R}$ software. For each age group, daily intakes are expressed in grams per day $(\mathrm{g} / \mathrm{d})$ and as a percentage of the energy intake excluding alcohol (EIEA) for LA and ALA, and in milligrams per day $(\mathrm{mg} / \mathrm{d})$ for EPA and DHA. These intakes are compared to the current ANSES recommendations, and the percentages of elderly people meeting these RDIs are calculated. Moreover, the percentages of elderly people ingesting the adequate levels of LA and ALA required for a healthy entire organism functioning are also calculated.

Similar to European Food Safety Authority (EFSA) and Food and Agriculture Organisation (FAO) / World Health Organisation (WHO), no specific dietary recommendations were formulated for elderly in France as in many European countries (5). Japan is the worldwide only country to define specific recommendations for total n-3 PUFAs for elderly, stratified by age (50-69 y, and over $70 \mathrm{y}$ ) and gender (9). Although France discussed the specific dietary needs of the elderly at the early 2000s, the current French RDIs for lipid and PUFA intake in elderly are similar to those for the adult population, as no specific needs for any of the PUFAs were deemed evident for this age group according to the updated ANSES recommendations (10).

The current French RDIs for lipid and PUFA intake in adult ( $>18$ years old) differ in terms of disease prevention towards the metabolic syndrome, diabetes and obesity, cardiovascular diseases, breast and colon cancers, neurological diseases and age-related macular degeneration. For the healthy adult population, the mean French RDIs for total lipid fat intake are included between
35 and $40 \%$ EIEA. The mean RDIs for LA and ALA are $4 \%$ EIEA and 1\% EIEA respectively, with a recommended LA/ALA ratio lower than 5. The mean RDIs for DHA and EPA+DHA are $250 \mathrm{mg} / \mathrm{d}$ and $500 \mathrm{mg} / \mathrm{d}$, respectively. Based on scientific data which generally deal with the effects of EPA+DHA, a $250 \mathrm{mg} / \mathrm{d}$ RDI-like figure is derived from the DHA and EPA+DHA RDIs to evaluate the adequacy of EPA intake. ANSES has also defined adequate intakes for LA, ALA and DHA as adequate n-6 and n-3 PUFA requirements to prevent dietary deficit in essential fatty acids and to ensure a proper functioning of the body. These intakes are 2 and $0.8 \%$ EIEA, respectively for LA and ALA, and $250 \mathrm{mg} / \mathrm{d}$ for DHA.

\section{Results}

Results are presented in Table 1 for the three age groups (65-69 y, 70-74 y, and 75-79 y), regardless of gender.

French elderly mean total fat intake figures meet the RDIs defined by ANSES (10), i.e. 35-40\% EIEA: figures are $37.8 \%$ EIEA (SD 6.2\%) for the 65 to 69 years old, $37.3 \%$ EIEA (SD 6.8\%) for the 70 to 74 years old, and 39.3\% EIEA (SD 6.2\%) for the 75 to 79 years old.

Mean intake of LA (4.2\% EIEA) was ranging from 4.1 to $4.4 \%$ EIEA, slightly higher than the ANSES RDI value (4\% EIEA). This intake increases with age, the 75 to 79 years old group having the highest mean intake. About $95 \%$ of the elderly of the 65-69 and 75-79 years old groups met as a minimum LA intake recommendation (i.e. 2\% EIEA), compared to over $98 \%$ for the 70-74 years old elderly.

Average daily intake of ALA was 0.5\% EIEA for all age groups, half of the RDI value (1\% EIEA). Regarding the adequate daily intake for this PUFA (0.8\% EIEA), from 5\% to $8.8 \%$ of the elderly satisfy this intake, this percentage increasing with age. The low intake of ALA associated with an intake of LA in accordance with the RDI leads to a LA/ALA ratio between 9 and 10, whereas ANSES recommendation is inferior to 5 .

The average daily intakes of DHA and EPA were 159 and $118 \mathrm{mg} / \mathrm{d}$, respectively, ranging from 157 (65-69 y) to 164 (70-74 y) mg/d for DHA (RDI: $250 \mathrm{mg} / \mathrm{d}$ ), and from $110(75-79$ y) to 129 (70-74 y) mg/d for EPA (RDI: 250 $\mathrm{mg} / \mathrm{d})$.

Despite these variations, there was no difference in LA, ALA, EPA and DHA dietary intakes based on age.

According to gender (data not shown), elderly men have a higher total energy intake than elderly women (from 21 to $28.5 \%$ higher depending on the age group). The mean daily intakes of LA, ALA, and EPA expressed in grams per day were higher in men than in women, but no differences were observed when expressed as a percentage of EIEA. The only recorded significant difference concerned the mean daily intake of ALA of the 65 - to 69-year-old women $(0.48 \%$ EIEA, SD $0.18 \%)$ compared to men of the same group age ( $0.42 \%$ EIEA, SD $0.16 \%)$. 
Table 1

Mean daily intakes of main polyunsaturated fatty acids of the French elderly population (INCA 2-Ciqual) (Mean values and standard deviations; percentages, and 95\% confidence intervals)

\begin{tabular}{|c|c|c|c|c|c|c|}
\hline & \multicolumn{6}{|c|}{ Mean daily intake INCA 2} \\
\hline & \multirow[b]{2}{*}{$\begin{array}{l}\text { ANSES RDIs }+ \text { and } \\
\text { adequate intakes } \neq\end{array}$} & \multicolumn{2}{|c|}{$\%$ EIEA * } & \multicolumn{2}{|c|}{$\mathrm{g} / \mathrm{d}, \mathrm{mg} / \mathrm{d}$} & \multirow[b]{2}{*}{$\begin{array}{c}\% \text { meeting } \S \text { ANSES } \\
\text { RDIs and adequate } \\
\text { intakes }(95 \% \mathrm{CI})\end{array}$} \\
\hline & & Mean & SD & Mean & SD & \\
\hline \multicolumn{7}{|c|}{ 65-69 years $(n=181 \mathrm{w}, 150)||$} \\
\hline Total fat & $35 \%-40 \%+$ & 37.8 & 6.2 & $81.7 \mathrm{~g}$ & 26.7 & $38.3(29.6,47)$ \\
\hline \multirow[t]{2}{*}{ LA $(18: 2 n-6)$} & $4 \%+$ & 4.1 & 1.9 & $9.0 \mathrm{~g}$ & 5.1 & $45.7(36.8,54.7)$ \\
\hline & $2 \% \neq$ & & & & & $95.1(91.3,99)$ \\
\hline \multirow[t]{2}{*}{$\operatorname{ALA}(18: 3 n-3)$} & $1 \%+$ & 0.5 & 0.2 & $1.0 \mathrm{~g}$ & 0.5 & $2.3(-0.4,5)$ \\
\hline & $0.8 \% \neq$ & & & & & $5(1.4,8.7)$ \\
\hline LA/ALA & $<5+$ & \multicolumn{4}{|c|}{$9.8(5.2)$} & $8.1(3.1,13.1)$ \\
\hline EPA (20:5n-3) & $250 \mathrm{mg} / \mathrm{d}+$ & 0.05 & 0.05 & $114 \mathrm{mg}$ & 100 & $6.8(2.6,11)$ \\
\hline DHA (22:6n-3) & $250 \mathrm{mg} / \mathrm{d}+$ & 0.08 & 0.06 & $157 \mathrm{mg}$ & 125 & $21.7(14.1,29.3)$ \\
\hline $\mathrm{EPA}+\mathrm{DHA}$ & $500 \mathrm{mg} / \mathrm{d}+$ & 0.13 & 0.11 & $271 \mathrm{mg}$ & 219 & $14.2(7.8,20.6)$ \\
\hline \multicolumn{7}{|c|}{$70-74$ years $(n=135 w, 114)||$} \\
\hline Total fat & $35 \%-40 \%+$ & 37.3 & 6.8 & $79.4 \mathrm{~g}$ & 25.6 & $28.5(18.8,38.2)$ \\
\hline \multirow[t]{2}{*}{ LA $(18: 2 n-6)$} & $4 \%+$ & 4.2 & 2.3 & $8.7 \mathrm{~g}$ & 4.3 & $37.7(27.3,48)$ \\
\hline & $2 \% \neq$ & & & & & $98.2(95.5,100.9)$ \\
\hline \multirow[t]{2}{*}{$\operatorname{ALA}(18: 3 n-3)$} & $1 \%+$ & 0.5 & 0.3 & $1.0 \mathrm{~g}$ & 0.5 & $2.5(0.1,5)$ \\
\hline & $0.8 \% \neq$ & & & & & $8(2.4,13.5)$ \\
\hline LA/ALA & $<5+$ & \multicolumn{4}{|c|}{$9.5(6.5)$} & $5.4(0.9,10)$ \\
\hline EPA $(20: 5 n-3)$ & $250 \mathrm{mg} / \mathrm{d}+$ & 0.06 & 0.07 & $129 \mathrm{mg}$ & 204 & $11(4.6,17.4)$ \\
\hline DHA (22:6n-3) & $250 \mathrm{mg} / \mathrm{d}+$ & 0.07 & 0.08 & $164 \mathrm{mg}$ & 226 & $17.1(9.7,24.5)$ \\
\hline $\mathrm{EPA}+\mathrm{DHA}$ & $500 \mathrm{mg} / \mathrm{d}+$ & 0.13 & 0.15 & $293 \mathrm{mg}$ & 421 & $12.5(5.7,19.2)$ \\
\hline \multicolumn{7}{|c|}{$75-79$ years $(n=103 \mathrm{w}, 84)$} \\
\hline Total fat & $35 \%-40 \%+$ & 39.3 & 6.2 & $78.7 \mathrm{~g}$ & 22.5 & $26.3(16.4,36.2)$ \\
\hline \multirow[t]{2}{*}{ LA $(18: 2 n-6)$} & $4 \%+$ & 4.4 & 2.4 & $8.6 \mathrm{~g}$ & 4.1 & $52.3(40.6,64)$ \\
\hline & $2 \% \neq$ & & & & & $94.7(89.6,99.8)$ \\
\hline \multirow[t]{2}{*}{$\operatorname{ALA}(18: 3 n-3)$} & $1 \%+$ & 0.5 & 0.2 & $1.0 \mathrm{~g}$ & 0.5 & $4.9(-0.4,10.2)$ \\
\hline & $0.8 \% \neq$ & & & & & $8.8(2.2,15.4)$ \\
\hline LA/ALA & $<5+$ & \multicolumn{4}{|c|}{$9.9(6.3)$} & $5.4(0.5,10.3)$ \\
\hline EPA (20:5n-3) & $250 \mathrm{mg} / \mathrm{d}+$ & 0.06 & 0.05 & $110 \mathrm{mg}$ & 99 & $12.2(4.7,19.8)$ \\
\hline DHA (22:6n-3) & $250 \mathrm{mg} / \mathrm{d}+$ & 0.08 & 0.07 & $158 \mathrm{mg}$ & 138 & $18.9(9.3,28.4)$ \\
\hline $\mathrm{EPA}+\mathrm{DHA}$ & $500 \mathrm{mg} / \mathrm{d}+$ & 0.14 & 0.12 & $267 \mathrm{mg}$ & 233 & $16.8(7.9,25.7)$ \\
\hline \multicolumn{7}{|c|}{$\begin{array}{l}\text { LA, linoleic acid; ALA, alpha-linolenic acid; EPA, eicosapentaenoic acid; DHA, docosahexaenoic acid; * \% EIEA, percentage of total energy intake excluding alcohol; }+ \\
\text { ANSES RDIs, French Agency for Food, Environmental and Occupational Health \& Safety (ANSES) recommended dietary intakes (RDIs). ANSES RDIs for adults are } \\
\text { expressed as \% EIEA for LA and ALA ( } 4 \text { and } 1 \% \text { EIEA, respectively), with a recommended LA/ALA ratio lower than 5, and as mg/d for DHA ( } 250 \mathrm{mg} / \mathrm{d} \text { ), EPA+DHA } \\
\text { ( } 500 \mathrm{mg} / \mathrm{d} \text { ), and EPA ( } 250 \mathrm{mg} / \mathrm{d} \text { RDI-like figure derived from the DHA and EPA+DHA RDIs); } \neq \text { Adequate intakes of LA and ALA ( } 2 \text { and } 0.8 \% \text { EIEA, respectively) } \\
\text { to avoid any essential fatty acid dietary deficit-related syndrome and to satisfy n- } 6 \text { and n-3 PUFA human requirements for the proper functioning of the organism, } \\
\text { notably development and brain functioning; } \S \text { Percentage of elderly meeting ANSES RDIs (considered as } \geq 4 \% \text { for LA, } \geq 1 \% \text { for ALA, } \geq 250 \mathrm{mg} \text { for EPA and DHA and } \\
\geq 500 \mathrm{mg} \text { for EPA+DHA for the calculation of percentages meeting the respective RDIs) or ingesting adequate levels of LA and ALA (considered as } \geq 2 \% \text { and } \geq 0.8 \% \text { for } \\
\text { the calculation of percentages meeting the respective adequate intakes for LA and ALA); I I Population size is given as weighted first (w) and raw after. For example, } \\
\text { there were } 150 \text { elderly aged } 65-69 \text { in the survey but they are counted as } 181 \text { in the statistics presented so that the proportion of elderly at this age is representative of the } \\
\text { French population. }\end{array}$} \\
\hline
\end{tabular}


Taken together our data show that the overall elderly population (over than 95\%) for ALA and between $83 \%$ (75-79 y) and $88 \%$ (70-74 y) of the elderly population for EPA+DHA do not meet ANSES RDIs for n-3 PUFAs.

\section{Discussion}

From this study, it emerges an inadequacy of the n-3 PUFA intakes of the French elderly population (65-79 y) with the RDIs. Specifically, besides an adequate total fat daily intake and a LA daily intake close or superior to the RDI (from 4.1 to $4.4 \%$ EIEA vs $4 \%$ EIEA), the French elderly have, regardless of age and gender, a low mean dietary ALA intake equal half of the RDI $(0.5 \%$ EIEA vs $1 \%$ EIEA), and a mean dietary DHA intake close to two-thirds of the ANSES recommendation (i.e. from 154 to $167 \mathrm{mg} / \mathrm{d}$ vs $250 \mathrm{mg} / \mathrm{d}$ ). These translated into a LA/ALA ratio between 9.5 and 9.9, twice as high as the recommended threshold inferior to 5 , and a mean dietary EPA+DHA intake (from 267 to $293 \mathrm{mg} / \mathrm{d}$ ) slightly more than half of the RDI $(500 \mathrm{mg} / \mathrm{d})$. These mean dietary intakes are slightly higher than those described for the French adult population (6). The major food contributors to PUFA intake in French elderly are vegetable oils (25.5\%) and condiments and sauces (12.9\%) for LA, vegetable oils (14.7\%) and margarine $(11.1 \%)$ for ALA. Concerning the n-3 long chain PUFAs, the main contributor for DHA and EPA was fish $(60.1 \%$ and $54.3 \%$, respectively). Although vegetable oils and fish are the main dietary sources of ALA, and DHA+EPA, respectively, it seems that the inadequacy of the mean n-3 PUFA dietary intakes of elderly with the RDIs may be due to a not sufficient dietary intake of these foods, even if elderly have higher mean intakes for these foods than adults (11).

To date, very few studies have focused on PUFA intake of the European and French elderly population (5). In France, only two studies prior to INCA 2 study have reported such data. The first one concerned 1786 elderly community dwellers (age range 67.7-94.9 years old) from Bordeaux, included in the Three-City cohort, in which mean dietary intakes were stratified in age (65$74 \mathrm{y}, 75-84 \mathrm{y}$, and $\geq 85 \mathrm{y})$, and gender $(4,12)$. From data collected in 2001/2002, regardless of age and gender, the mean dietary intakes of the 1786 elderly were $3.35 \%$ of energy intake (EI) (SD 2.35\%), and 0.40\% EI (SD 0.32\%), respectively for LA and ALA, leading to a LA/ALA ratio of 9.9 (SD 7.05). Concerning n-3 long chain PUFAs, mean dietary intakes of EPA and DHA were $140 \mathrm{mg} / \mathrm{d}$ (SD 340 $\mathrm{mg} / \mathrm{d}$ ) and $280 \mathrm{mg} / \mathrm{d}(\mathrm{SD} 690 \mathrm{mg} / \mathrm{d}$ ), respectively. The intake of EPA was below recommended levels by ANSES $(250 \mathrm{mg} / \mathrm{d})$, while the mean consumption of DHA was close to the recommended intake. Gender only affects the total fat intake (lower in men than in women when expressed in proportion of EI), and no impact on the mean dietary intakes of LA, ALA, EPA and DHA. This cohort of elderly of southwestern France had higher mean
EPA and DHA dietary intakes than those observed in the INCA 2 study but with very large ranges of intakes due to great inter-individual variability. Knowing that the main source of EPA and DHA is fish, a food not consumed daily in the Three-City cohort, the authors argued that these results might probably due to the single $24 \mathrm{~h}$ recall used which allows a good estimation of the mean but not of the variance of the consumption. Besides, compared to the present results, the mean dietary intakes of LA and ALA were slightly lower, but leading to a similar LA/ ALA ratio. In conclusion, it emerged from this study that these elderly have an unbalanced fatty acid intake, characterized notably by a deficit of n-3 PUFAs.

The second French study is the CALIPSO survey which was conducted in four French coastal regions, in 1011 high seafood consumers (fish and seafood at least twice weekly) aged 18 years old and over, among which 123 older subjects ( $\geq 65$ years old) (13). The mean EPA and DHA dietary intakes of the 123 older subjects were 467 $\mathrm{mg} / \mathrm{d}$ (SD $468 \mathrm{mg} / \mathrm{d}$ ) and $819 \mathrm{mg} / \mathrm{d}(\mathrm{SD} 737 \mathrm{mg} / \mathrm{d}$ ), respectively, three to four times higher than the mean dietary intakes observed in the INCA 2 study. Concerning ALA, the mean dietary intakes of elderly (from $43 \mathrm{mg} / \mathrm{d}$ (SD $27 \mathrm{mg} / \mathrm{d}$ ) to $95 \mathrm{mg} / \mathrm{d}$ (SD $88 \mathrm{mg} / \mathrm{d}$ ) according to the coastal region) covered between 2 to $4.3 \%$ of the RDI for this PUFA. These values are much lower than those observed for the elderly in the INCA 2 study (half of the RDI value), due to the fact that the CALIPSO survey only studied the fish and seafood consumption and its contribution to n-3 long chain PUFA intakes (including ALA). Although the comparison with our results is rather difficult, these results show however that consumption of fish and seafood twice weekly allowed elderly to reach the n-3 long chain PUFA RDIs.

In Europe, in addition of the two French studies, nine studies from eight other countries have reported intake data for elderly aged $\geq 65$ years old (for eight of them, the last one reporting data in elderly $\geq 60$ years old) with different levels of accuracy according to the different PUFAs (5). From these studies, it emerges that mean LA and ALA intakes can be higher (6-7\% EI for LA, $0.6 \%$ EI for ALA), lower (2.6\% EI for LA, $0.2 \%$ EI for ALA) or close to that which are observed in the present study. Concerning EPA and DHA, a variability has also been observed between countries, with a mean dietary intake of EPA ranging from 50 to $283 \mathrm{mg} / \mathrm{d}$ and a mean dietary intake of DHA ranging from 80 to 631 $\mathrm{mg} / \mathrm{d}$. As mentioned by Sioen et al., the heterogeneity of the n-3 PUFA dietary intakes between the different studies could be due to the different methods used for dietary assessments (e.g. $24 \mathrm{~h}$ recall, food frequency questionnaires, dietary record) which may not capture the intake of foods that are not consumed on a daily basis such as fish and seafood, hence leading to n-3 PUFA intakes incorrectly estimated (5).

According to notices of AFSSA (former name of ANSES), about dietary requirements of elderly people suffering from some specific diseases, and WHO, about 
aging, elderly constitute a heterogeneous population in terms of health with altered nutrient requirements. These specific requirements are driven by modifications in body composition, physical activity, altered nutrient intake because of low variety of food consumed, reduced appetite, loss of sensory appreciation of food, dentition and swallowing problems, the presence of disease and social issues. Taken together, these changes may expose elderly to a high risk of inadequate PUFA intake, besides other important micronutrients $(14,15)$.

In the elderly, nutrition is one of the major determinants of successful aging, defined as the ability to maintain low risk of disease and disease-related disability, high mental and physical function and active engagement of life (16). Knowledge of nutrient requirements of older adults is growing yet is still inadequately documented. Older adults may have unique nutrients needs. The quantity of food and energy intake usually decreases substantially across the spectrum of aging, as observed in our study. Surprisingly, there is a lack of information about fatty acids, mainly n-3 longchain PUFAs.

As proof, no recommendations from international and European organizations exist for elderly, as no specific needs for any of the PUFAs were deemed evident. As already mentioned, Japan is the only country to have PUFA dietary intake recommendations for elderly (9). These RDIs are based on the following considerations that for the elderly, weakening of their masticatory function, deterioration of digestive and absorptive function, and reduction in food intake due to less physical activities exist. Characteristics of this age group include frequent and wide variation of their individual food intake and the fact that many aged individuals are affected by an illness. The last update of the RDIs for Japanese elderly people, regarding the importance of issues involved with under-nutrition, nutritional deficiency as well as overnutrition, reviewed scientific data about associations between energy or nutrients and frailty or sarcopenia. Japan set RDIs for total n-3 PUFA four to five times higher that French RDIs with mean dietary intakes higher for Japanese men than for women due to studies reporting that male older adults are more vulnerable in terms of nutrient intake compared with females. This is not only to prevent energy or nutrient deficiency that may be caused by inadequate nutrient intake, but also for the primary prevention of lifestyle-related diseases (9).

In France, the previous update of the French RDIs had set specific recommendations for the elderly ( $>$ 75 y) (17). These recommendations were based on in vivo data (n-3 PUFA blood status), on the described roles of the n-3 PUFAs, and on the fact that n-3 PUFA deficiency was associated with skin, ocular, metabolic and cognitive disorders, and that the occurrence of thrombotic, inflammatory, immune disorders and several pathological conditions (osteoporosis, sarcopenia, neurodegenerative diseases) increases with age. Taken together, and due to the fact that the activity of the desaturase enzyme, which converts essential precursors in longer-chain PUFAs, might be decreased in ageing, these data were in favor of n-3 PUFA RDIs for elderly. However, the last update of the French RDIs did not maintain specific recommendations for this age group. ANSES indeed reassessed the ALA and DHA RDIs for adult with increased mean dietary intakes, and, due to the lack of specific data for elderly suggesting that dietary needs of aged people may be different from adult ones, concluded that RDIs for adults also apply to elderly (10).

In conclusion, data collected from the INCA 2 survey evidence that $97 \%$ of the elderly population do not meet the RDIs for ALA versus more than $80 \%$ the RDIs for EPA+DHA. Detailed data of the third study on the food consumption and eating habits of the French population (INCA 3) (performed in 2014 and 2015) are expected in the next few months and will allow monitoring the evolution of PUFA dietary intakes for the different age groups of the French elderly population.

Nevertheless, the lack of specific RDIs for elderly raises questions about the importance of n-3 PUFAs for this age group. More and more scientific data reported that optimal nutrition is one of the most important determinants of healthier ageing, reducing the risk of disability, maintaining mental and physical functions, thus preserving and ensuring a better quality of life. Among the specific nutrients able to play a key role, n-3 PUFAs might have the potential of preventing and reducing co-morbidities in older adults, including rheumatoid arthritis, depression and macular degeneration. More precisely, n-3 PUFA status and dietary intake may have beneficial effects on cardiovascular system (atherosclerosis, arrhythmias), immune function (immune cell proliferation, proinflammatory cytokines, other cellular effects), muscle performance (muscle mass and function) and bone health in older adults. In addition, given their beneficial effects on brain function (dementia, depression and cognitive function), n-3 long-chain PUFAs appear to be neuroprotective and may also have unique properties in affecting neurobiology, both of critical interest during the aging process. Indeed, in contrast to their proposed actions in childhood, where they are required for healthy development of brain tissue, in older age n-3 PUFAs are more like to act in a protective and health maintaining manner $(16,18,19)$.

N-3 PUFAs are so now identified as potential key nutrients, safe and effective in the treatment and prevention of several negative consequences of ageing. The available data encourage higher intakes of $n-3$ PUFAs, and recommendations for intake of these fatty acids should be developed for the elderly population.

Funding: This work was supported by grants of Terres Univia (France).

Author contributions: BB, JT, PG, NS, and SP conceptualized the study. BB wrote the manuscript. JT processed the statistical analysis. All authors read and approved the final version.

Conflict of interest statement: JT and SP reported grants from Terres Univia during the conduct of the study. BB, PG, and NS have no conflicts of interest to 
declare.

Ethical standards: The French INCA 2 dietary survey was approved by the French Data Protection Authority (Commission Nationale de 1'Informatique et des Libertés $n^{\circ} 2003$ X727AU) and the French National Council for Statistical Information (Conseil National de l'Information Statistique).

\section{References}

1. Skeaff CM, Miller J. Dietary fat and coronary heart disease: summary of evidence from prospective cohort and randomised controlled trials. Ann Nutr Metab 2009; 55(1-3):173-201. doi: 10.1159/000229002

2. Mozaffarian D. Does alpha-linolenic acid intake reduce the risk of coronary heart disease? A review of the evidence. Altern Ther Health Med 2005; 11(3):24-30; quiz 31, 79

3. Aranceta J, Pérez-Rodrigo C. Recommended dietary reference intakes, nutritional goals and dietary guidelines for fat and fatty acids: a systematic review. Br J Nutr 2012; 107 Suppl 2:S8-22. doi: 10.1017/S0007114512001444

4. Féart C, Jutand MA, Larrieu S, Letenneur L, Delcourt C, Combe N, et al. Energy, macronutrient and fatty acid intake of French elderly community dwellers and association with socio-demographic characteristics: data from the Bordeaux sample of the Three-City Study. Br J Nutr 2007; 98(5):1046-57

5. Sioen I, van Lieshout L, Eilander A, Fleith M, Lohner S, Szommer A, et al. Systematic Review on N-3 and N-6 Polyunsaturated Fatty Acid Intake in European Countries in Light of the Current Recommendations - Focus on Specific Population Groups. Ann Nutr Metab 2017; 70:39-50. doi: $10.1159 / 000456723$

6. Tressou J, Moulin P, Vergès B, Le Guillou C, Simon N, Pasteau S. Fatty acid dietary intake in the general French population: are the French Agency for Food, Environmental and Occupational Health \& Safety (ANSES) national recommendations met? Br J Nutr 2016; 116:1966-1973. doi: 10.1017/ S000711451600413X

7. French Agency for Food, Environmental and Occupational Health \& Safety. Actualisation des apports nutritionnels conseillés pour les acides gras. Rapport d'expertise collective 2011. 2011. https: / www.anses.fr/fr/system/ files/NUT2006sa0359Ra.pdf. Accessed 30 Aug 2017

8. French Agency for Food, Environmental and Occupational Health \& Safety. Avis et rapport de l'Anses relatifs aux «Apports en acides gras de la population vivant en France. Comparaison aux apports nutritionnels conseillés définis en 2010». 2015. https://www.anses.fr/fr/system/files / NUT2014sa0117Ra.pdf. Accessed 30 Aug 2017

9. National Institute of Health and Nutrition. Overview of Dietary Reference Intakes for Japanese (2015). 2015. http://www.mhlw.go.jp/file/06Seisakujouhou-10900000-Kenkoukyoku/Overview.pdf Accessed 14 November 2017

10. French Agency for Food, Environmental and Occupational Health \& Safety. Avis et rapport de l'ANSES relatifs aux «Apports en acides gras de la population vivant en France. Comparaison aux apports nutritionnels conseillés définis en 2010». 2015. https://www.anses.fr/fr/system/files / NUT2014sa0117Ra.pdf. Accessed 14 November 2017

11. French Food Safety Agency. Rapport de l'Agence française de sécurité sanitaire des aliments sur l'Etude Individuelle Nationale des Consommations Alimentaires 2 (INCA 2) (2006-2007). 2009. https://www.anses.fr/fr/ system/files/PASER-Ra-INCA2.pdf. Accessed 14 November 2017

12. Feart C, Alles B, Merle B, Samieri C, Barberger-Gateau P. Adherence to a Mediterranean diet and energy, macro-, and micronutrient intakes in older persons. J Physiol Biochem 2012; 68(4):691-700. doi: 10.1007/s13105-0120190-y

13. Bemrah N, Sirot V, Leblanc JC, Volatier JL. Fish and seafood consumption and omega 3 intake in French coastal populations: CALIPSO survey. Public Health Nutr 2008; 12(5):599-608. doi: 10.1017/S1368980008002681

14. World Health Organization Nutrition for Older Persons. 2015. http: / / www. who.int/nutrition/topics/ageing/en/index1.html. Accessed 14 November 2017

15. French Food Safety Agency. Avis de 1'Agence française de sécurité sanitaire des aliments sur l'évaluation des besoins nutritionnels chez les personnes âgées fragiles ou atteintes de certaines pathologies afin de définir des références nutritionnelles permettant d'adapter leur prise en charge nutritionnelle. 2009. https: / / www.anses.fr/fr/system/files / NUT2008sa0279. pdf. Accessed 14 November 2017

16. Ubeda N, Achón M, Varela-Moreiras G. Omega 3 fatty acids in the elderly. Br J Nutr 2012; 107 Suppl 2:S137-51. doi: 10.1017/S0007114512001535

17. Martin A. Apports nutritionnels conseillés pour la population française, 3rd edn. 2001. TEC \& DOC, Paris

18. Molfino A, Gioia G, Rossi Fanelli F, Muscaritoli M. The role for dietary omega-3 fatty acids supplementation in older adults. Nutrients 2014 6(10):4058-73. doi: $10.3390 /$ nu6104058

19. de Groot $\mathrm{CP}$, van Staveren WA. Nutritional concerns, health and survival in old age. Biogerontology 2010; 11(5):597-602. doi: 10.1007/s10522-010-9284-5 